\title{
International Year of the Periodic Table 2019: Elements Important for Life Sciences
}

\section{Division of Medicinal Chemistry and Chemical Biology}

\section{Boron in Medicinal Chemistry: Powerful, but Neglected}

\section{Patrick Mäder*}

${ }^{*}$ Correspondence: Dr. P. Mäder, Endotherm Life Science Molecules, Science Park II, 66123 Saarbrücken, Germany, E-mail: patrick.maeder@endotherm.de

\section{Keywords: Boron · Drug Discovery · Medicinal Chemistry}

Boron is a fascinating element due to its chemical versatility. In nature, boron can be found as boric acid (1, Fig. 1A), which is essential for plants due to its pivotal function in cell wall synthesis (cross linking of pectin in the primary cell wall), protein synthesis, germination and pollination, and increase of sugar translocation. ${ }^{11]}$ Synthetic boron-containing compounds are well investigated due to their unique properties and widespread applications. In organic chemistry, boronic acids $\left(\mathrm{R}-\mathrm{B}[\mathrm{OH}]_{2}\right)$, or their derivatives are commonly used. Boron has a deficiency of two valence electrons and possesses a vacant $\mathrm{p}$-orbital. As a consequence, the neutral form of boronic acids ( $\mathrm{pK}$ between 6 and 9 for substituted phenylboronic acids, 2, Fig. 1) show a trigonal planar geometry, but allow conversion to $\mathrm{sp}^{3}$-hybridized boron (by coordination of a hydroxyl group), resulting in tetrahedral adducts with a carbon-like configuration (see Fig. 1A). Boronic acids are also mild Lewis acids, chemically stable

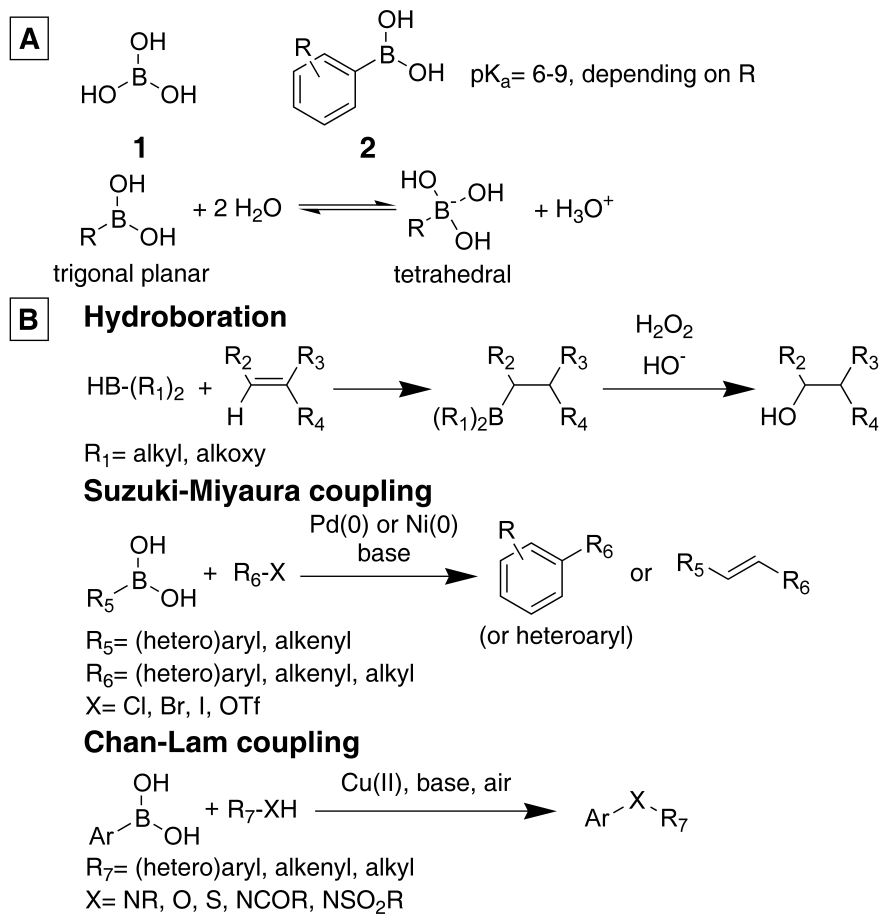

Fig. 1. Properties (part A) and selected synthetic applications (part B) of organoboron compounds. ${ }^{[2,3]}$ and easy to handle.[2] Therefore, organoboron compounds represent an attractive class of synthetic intermediates (examples are depicted in Fig. 1B), e.g. in hydroborations $(\mathrm{C}-\mathrm{H} / \mathrm{C}-\mathrm{OH}$ bond formation), in the Noble-prize awarded Suzuki-Miyaura coupling $(\mathrm{C}-\mathrm{C}$ bond formation), or in Chan-Lam coupling (C-N/C-O bond formation). ${ }^{[3]}$

Even though boron, in the form of boric acid (1), is known as a mild antiseptic since the early 19th century, the use of boron in medicinal chemistry and drug discovery has been neglected. ${ }^{4]}$ The main reason for this may be due to the unfounded assumption that boron is unstable and toxic. Although boric acid (1), the major metabolite of organoboron compounds, is as toxic as sodium chloride $\left(\mathrm{LD}_{50}\left(\mathrm{~B}(\mathrm{OH})_{3}\right)=2660 \mathrm{mg} / \mathrm{kg}\right.$ (rat, oral); $\mathrm{LD}_{50}(\mathrm{NaCl})$ $=3000 \mathrm{mg} / \mathrm{kg}$ (rat, oral $)$ ), the mindset of medicinal chemists was always like this: "Only a moron would put boron in a drug!"'[5]

With the FDA-approval of bortezomib (3, Fig. 2) in 2003, the first boron-containing drug for treatment of non-Hodgkin's lymphoma and multiple myeloma, the mindset of the medicinal chemistry community concerning boron seemed to change. Additionally, it was the first-in-class 26S proteasome inhibitor. The proteasome is the key regulator of (intracellular) protein degradation and pivotal for the disassembly of transcription factors or tumor suppressors. As a consequence, dysregulation of this process leads to uncontrolled cell cycle, which could result in tumor growth. The boronic acid moiety is the key player in the mode of action of bortezomib (3) due to the formation of a tetrahedral, pseudo-covalent complex by accepting a lone pair of electrons from the threonine residue in the active site, resulting

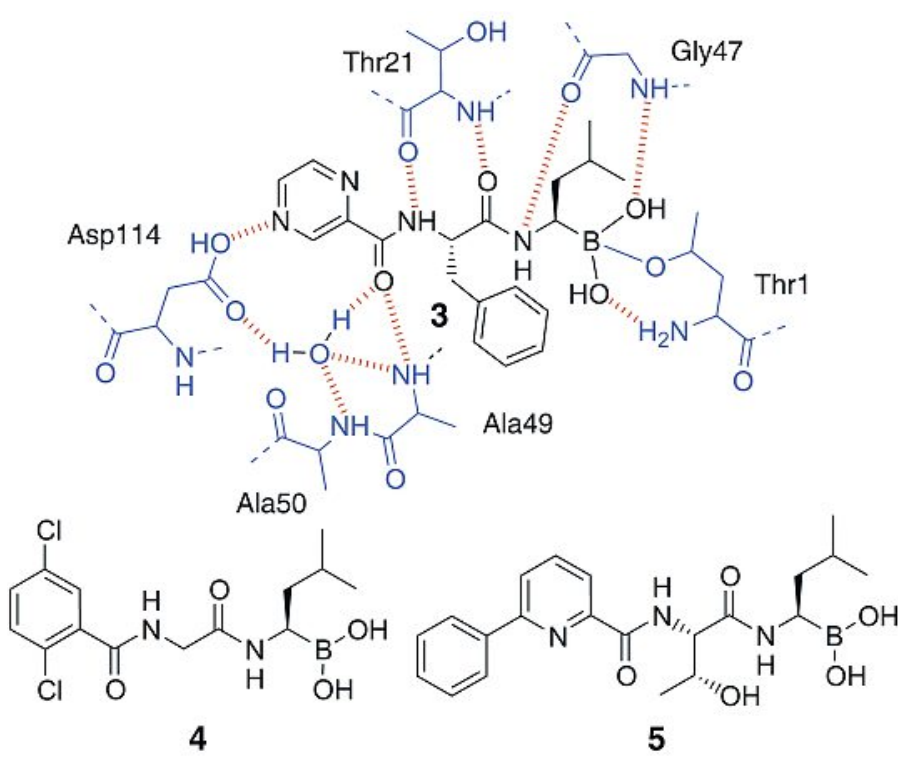

Fig. 2. Schematic overview of bortezomib (3) bound to the chymotrypsin-like active site of the proteasome (highlighted in blue) ${ }^{[6 \mathrm{~b}]}$ and chemical structures of second-generation proteasome inhibitors ixazomib (4) and delanzomib (5). ${ }^{[7]}$ 
in an inhibition of the proteasomes activity that could lead to growth arrest and apoptosis of cancer cells (Fig. 2). Bortezomib (3) is highly selective towards proteasome, since the boronic acid moiety can only react with hard oxygen nucleophiles in contrast to soft cysteine nucleophiles, which was a major drawback of early proteasome inhibitors based on a tripeptidyl aldehyde scaffold. Although it might be possible in theory, bortezomib (3) was found to be a weak inhibitor of serine proteases since serine proteases require longer peptide substrates. Bortezomib (3) was found to be metabolically stable, effective in vivo, and well tolerated by patients. ${ }^{[6]}$ Recently, second-generation proteasome inhibitors, e.g. ixazomib (4, approved in 2015) and delanzomib (5, currently in phase III clinical trials), were developed to overcome bortezomib (3) resistance. ${ }^{[7]}$

In light of the success of bortezomib (3), a reassessment of boron in medicinal chemistry has taken place. The number of boron-containing compounds in different stages of drug discovery is increasing, targeting a broad range of biological targets. For instance, there are two approved benzoxoborole-based drugs (Fig. 3): tavaborole (6) and crisaborole (7). Tavaborole (6) is a broad spectrum antifungal agent for topical treatment of onychomycosis. Its mode of action is based on inhibition of leucyl-tRNA synthetase, an aminoacyl-tRNA synthetase which is required for fungal protein biosynthesis, due to the formation of a tetrahedral leucyl-tRNA-tavaborole adduct. ${ }^{[8]}$ The interference of the fungal protein biosynthesis leads to growth arrest and finally to cell death and elimination of the infection. Crisaborole (7) is an antiinflammatory agent used for topical treatment of atopic dermatitis. It is an inhibitor of phosphodiesterase 4 (mainly PDE4B), which is involved in inflammatory processes and immune response due to the release of tumor necrosis factor alpha as well as several cytokines (e.g. IL-12, IL-23).[9]
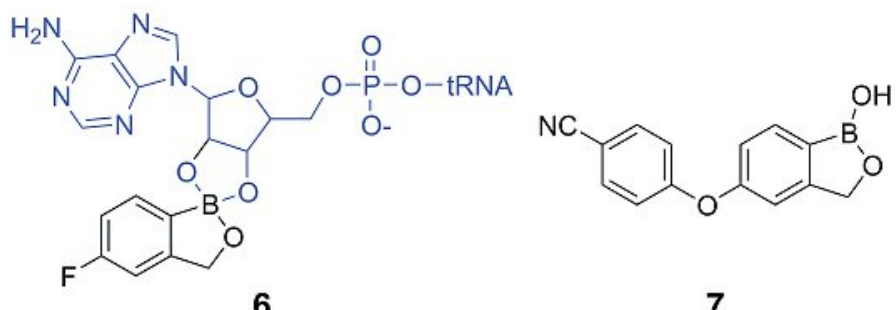

Fig. 3. Schematic overview of tavaborole (6) bound to the leucyltRNA synthetase (highlighted in blue) ${ }^{[\mathrm{b}]}$ and chemical structure of crisaborole (7). ${ }^{[9]}$

Additionally, an increasing number of boron-containing bioactive molecules can be found in literature. The activities of these compounds are highly versatile. Although the majority represents the class of serine protease inhibitors (e.g. beta-lactamase, thrombin, chymotrypsin, penicillin binding protein, HCV-NS3 serine protease, dipeptidyl peptidase IV), the following examples can be found: inhibitors of histon deacetylases, EGFR tyrosine kinase, carbonic anhydrase, mycotubercular enoyl reductase, arginase, as well as antineoplastic agents and anti-parasitic agents (African trypanosomiasis, malaria). ${ }^{[5,10]}$

Organoboron compounds were investigated in the context of drug delivery systems due to the pseudo-covalent bonding between boronic acids and diol-containing compounds (e.g. carbohydrates). As an example, type 1 diabetics suffer from a lack of continuous and feedback controlled release of insulin. To solve this problem, insulin-incorporating polymers based on boronic acids and unsaturated alcohols (e.g. vinyl alcohol), were developed. In the absence of glucose, these polymers form an impermeable layer. Since glucose has a higher affinity towards the boronic acid than the unsaturated alcohol of the polymer, an exchange of the two alcohols takes place, leading to a change of the polymer state, and thereby to a release of insulin. However, other sugars (e.g. fructose) as well as catechols possess similar or higher affinity than glucose, and therefore, these systems do not work reliably. These problems have to be addressed in future studies. ${ }^{[11]}$

In summary, the use of boron was ignored for a long time due to skepticism and toxicity concerns, but medicinal chemists by now are exploring the benefits of boron in drug discovery (relative to $\mathrm{C}, \mathrm{H}, \mathrm{N}, \mathrm{O}, \mathrm{S}$ ). There is a need of feasible synthetic routes to manipulate boron-containing compounds as well as the willingness to include boron in small molecules. The years to come are thus highly important regarding the outcome of boroncontaining compounds in clinical trials. However, the perspective is very promising that boron can become commonplace in drug discovery in the future, since the unique properties of boron offer a rare opportunity to explore and expand chemical space in medicinal chemistry.

Received: May 28, 2019

[1] a) W. Ahmad, A. Niaz, S. Kanwal, M. K. Rasheed, J. Agric. Res. 2009, 47, 329; b) L. Becker, A. Scheffczyk, B. Förster, J. Oehlmann, J. Princz, J. Römbke, T. Moser, J. Soils Sediments 2011, 11, 238.

[2] a) D. G. Hall in 'Boronic Acids: Preparation and Applications in Organic Synthesis, Medicine and Materials', Ed. D. G. Hall, Wiley-VCH Verlag GmbH \& Co. KGaA, Germany, 2011, pp 1-133; b) J. Kahlert, C. J. D. Austin, M. Kassiou, L. M. Rendina, Aust. J. Chem. 2013, 66, 1118.

[3] a) S. J. Geier, C. M. Vogels, S. A. Westcott in 'Boron Reagents in Synthesis', Ed. A. Coca, ACS Symposium Series, USA, 2016, pp 209-225; b) I. Maluenda, O. Navarro, Molecules 2015, 20, 7528; c) J. X. Qiao, P. Y. S. Lam in 'Boronic Acids: Preparation and Applications in Organic Synthesis, Medicine and Materials', Ed. D. G. Hall, Wiley-VCH Verlag GmbH \& Co. KGaA, Germany, 2011, pp 315-362.

[4] R. Piva, B. Ruggeri, M. Williams, G. Costa, I. Tamagno, D. Ferrero, V. Giai, M. Coscia, S. Peola, M. Massaia, Blood 2008, 111, 2765.

[5] S. J. Baker, C. Z. Ding, T. Akama, Y.-K. Zhang, V. Hernandez, Y. Xia, Future Med Chem. 2009, 1, 1275.

[6] a) A. Paramore, S. Frantz, Nat. Rev. Drug Discov. 2003, 2, 611; b) M. Groll, C. R. Berkers, H. L. Ploegh, H. Ovaa, Structure, 2006, 14, 451; c) R. L. Stein, Bioorg. Med. Chem. Lett. 1998, 8, 333; d) J. Adams, M. Kauffman, Cancer Invest. 2004, 22, 304.

[7] a) L. Kubiczkova, L. Pour, L. Sedlarikova, R. Hajek, S. Sevcikova, J. Cell. Mol. Med. 2014, 18, 947; b) A. Gozzetti, G. Papini, V. Candi, C. Z. Brambilla, S. Sirianni, M. Bocchia, Anti-Cancer Agents Med. Chem. 2017, 17,920 .

[8] a) N. Sharma, D. Sharma, J. Pharmacol. Pharmacother. 2015, 6, 236; b) F. L. Rock, W. Mao, A. Yaremchuk, M. Tukalo, T. Crépin, H. Zhou, Y. K. Zhang, V. Hernandez, T. Akama, S. J. Baker, J. J. Plattner, L. Shapiro, S. A. Martinis, S. J. Benkovic, S. Cusack, M. R. Alley, Science 2007, 316, 1759; c) S. J. Baker, Y.-K. Zhang, T. Akama, A. Lau, H. Zhou, V. Hernandez, W. Mao, M. R. K. Alley, V. Sanders, J. J. Plattner, J. Med. Chem. 2006, 49, 4447.

[9] a) F. Moustafa, S. R. Feldman, Dermatol. Online J. 2014, 20, 22608; b) R. Nazarian, J. M. Weinberg, Curr. Opin. Investig. Drugs 2009, 10, 1236.

[10] a) L. Ciani, S. Ristori, Expert Opin. Drug Discov. 2012, 7, 1017; b) D. B. Diaz, A. K. Yudin, Nat. Chem. 2017, 9, 731; c) A. Lapuebla, M. Abdallah, O. Olafisoye, C. Cortes, C. Urban, J. Quale, D. Landman, Antimicrob. Agents Chemother. 2015, 59, 4856; d) J. Brem, R. Cain, S. Cahill, M. A. McDonough, I. J. Clifton, J.-C. Jiménez-Castellanos, M. B. Avison, J. Spencer, C. W. G. Fishwick, C. J. Schofield, Nat. Commun. 2016, 7, 12406; e) P. C. Trippier, C. McGuigan, Med. Chem. Commun. 2010, 1, 183; f) G. F. Whyte, R. Vilar, R. Woscholski, J. Chem. Biol. 2013, 6, 161; g) W. Yang, X. Gao, B. Wang, Med. Res. Rev. 2003, 23, 346; h) P. V. Ramachandran, Future Med. Chem. 2013, 5, 611.

[11] a) S. Kitano, Y. Koyama, K. Kataoka, T. Okano, Y. Sakurai, J. Control Release 1992, 19, 162; b) G. Springsteen, B. Wang, Tetrahedron 2002, 58, 5291; c) F. Liu, S. C. Song, D. Mix, M. Baudy, S. W. Kim, Bioconjugate Chem. 1997, 8, 664; d) T. D. James, K. R. A. S. Sandanayake, R. Iguchi, S. Shinkai, J. Am. Chem. Soc. 1995, 117, 8982; e) H. Eggert, J. Frederiksen, C. Morin, J. C. Norrild, J. Org. Chem. 1999, 64, 3846; f) W. Yang, H. He, D. G. Drueckhammer, Angew. Chem. Int. Ed. 2001, 40, 1714; g) H. Cao, D. I. Diaz, N. DiCesare, J. R. Lakowicz, M. D. Heagy, Org. Lett. 2002, 4, 1503; h) V. R. Karnati, X. Gao, S. Gao, W. Yang, W. Ni, S. Sankar, B. Wang, Bioorg. Med. Chem. Lett. 2002, 12, 3373; i) L. Zhao, Q. Huang, Y. Liu, Q. Wang, L. Wang, S. Xiao, F. Bi, J. Ding, Materials 2017, 10, 170; j) D. Zhao, J.-Q. Xu, X.-Q. Yi, Q. Zhang, S.-X. Cheng, R.-X. Zhuo, F. Li, ACS Appl. Mater. Interfaces 2016, 8, 14845. 